\title{
Transformation of Pressurized Water Reactor AP1000 to Fuzzy Graph
}

\author{
${ }^{1}$ Azmirul Ashaari*, ${ }^{2}$ Tahir Ahmad and ${ }^{3}$ Wan Munirah Wan Mohamad \\ $\mathbf{1 , 2 , 3}$ Department of Mathematical Sciences, Faculty of Science \\ Universiti Teknologi Malaysia, 81310 Johor Bahru, Malaysia \\ ${ }^{2}$ Centre for Sustainable Nanomaterials, IbnuSina Institute for Scientific and Industrial Research, \\ Universiti Teknologi Malaysia, 81310 Johor Bahru, Malaysia \\ ${ }^{*}$ Corresponding author: mierul2000@gmail.com
}

Article history

Received: 14 November 2017

Received in revised form: No revision

Accepted: 10 December 2017

Published on line: 1 December 2018

\begin{abstract}
Pressurized water reactor (PWR) type AP1000 is a third generation of a nuclear power plant. The primary system of PWR using uranium dioxide to generate heat energy via fission process. The process influences temperature, pressure and $\mathrm{pH}$ value of water chemistry of the PWR. The aim of this paper is to transform the primary system of PWR using fuzzy autocatalytic set (FACS). In this work, the background of primary system of PWR and the properties of the model are provided. The simulation result, namely dynamic concentration of PWR is verified against published data.
\end{abstract}

Keywords Pressurized water reactor (PWR); autocatalytic set; fuzzy graph

Mathematics Subject Classification 05C50, 82C20, 94C15

\section{Introduction}

In 2010, Sovacool [1] has reported that, there were about $60 \%$ of all nuclear-related accidents occurred in the USA even though some modification and improvement were carried out by various researchers. The most important factor that needs to be considered is the quality and quantity of chemical compounds that involve inside nuclear power plant. Pressurized water reactor (PWR) is a nuclear power plant, which use light water as coolant and moderator. During operation of PWR, the moderator remains in a liquid state despite of high temperature inside the reactor due to the high pressure within primary coolant loop (see Figure 1).

The flow of the moderator begins inside a reactor vessel when the moderator is being heated by nuclear fission. In general, the fission process occurs when an atom U-235 captures a neutron. Subsequently, this atom is separated into two major compounds with released heat energy (see Figure 2). The hot moderator in a reactor vessel is transferred to pressurizer. The role of a pressurizer is to control the temperature of the moderator and the pressure of the system at certain level before transferred to steam generator. The moderator of a secondary system 
absorbs the heat from the moderator of a primary system inside a steam generator. This process is important in order a moderator of a secondary system change from water to steam. The moderator of primary system is then transferred back into the reactor vessel via reactor coolant pump. This process is repeated until the PWR reactor is shut down.

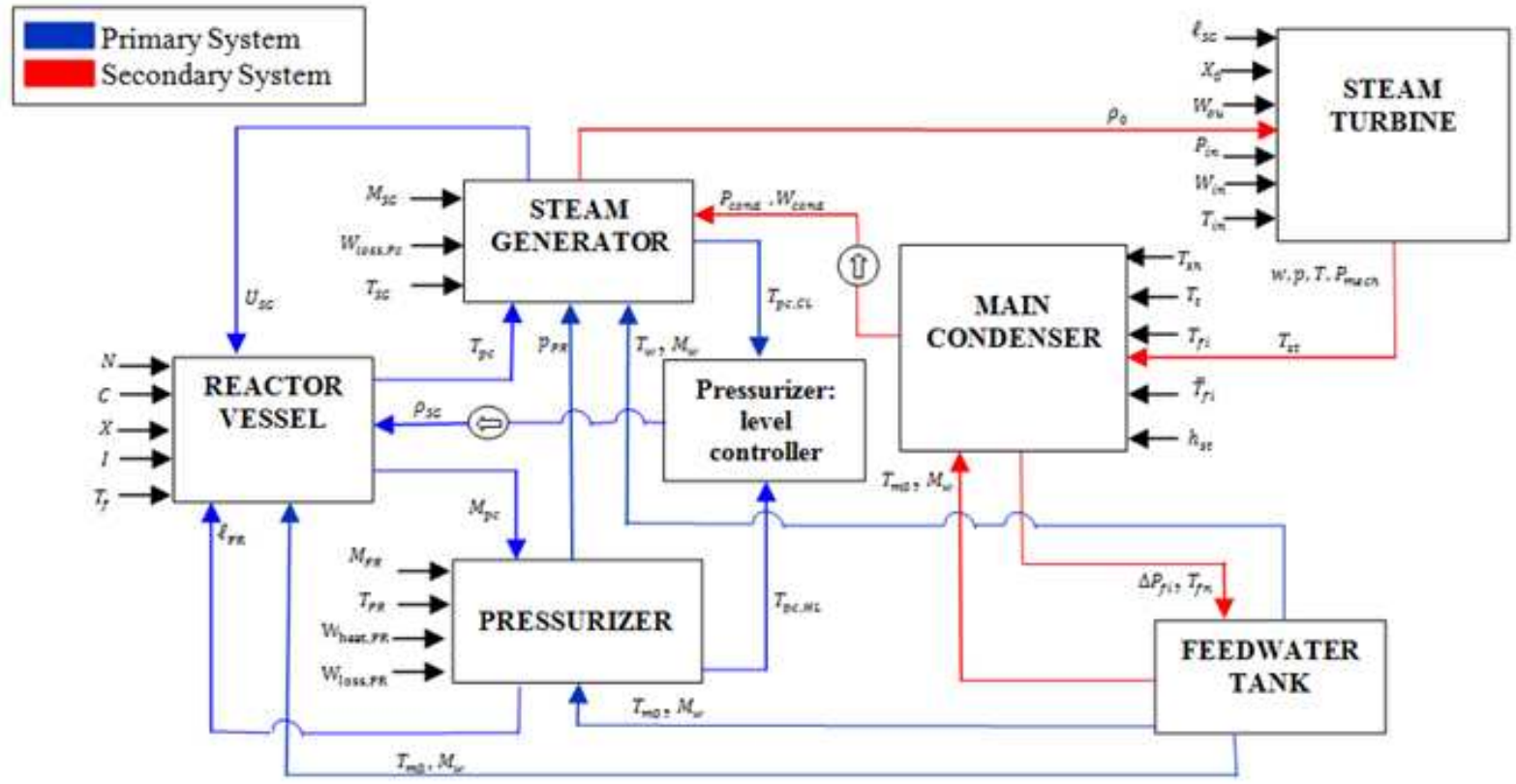

Figure 1: Pressurizer Water Reactor Block Diagram System

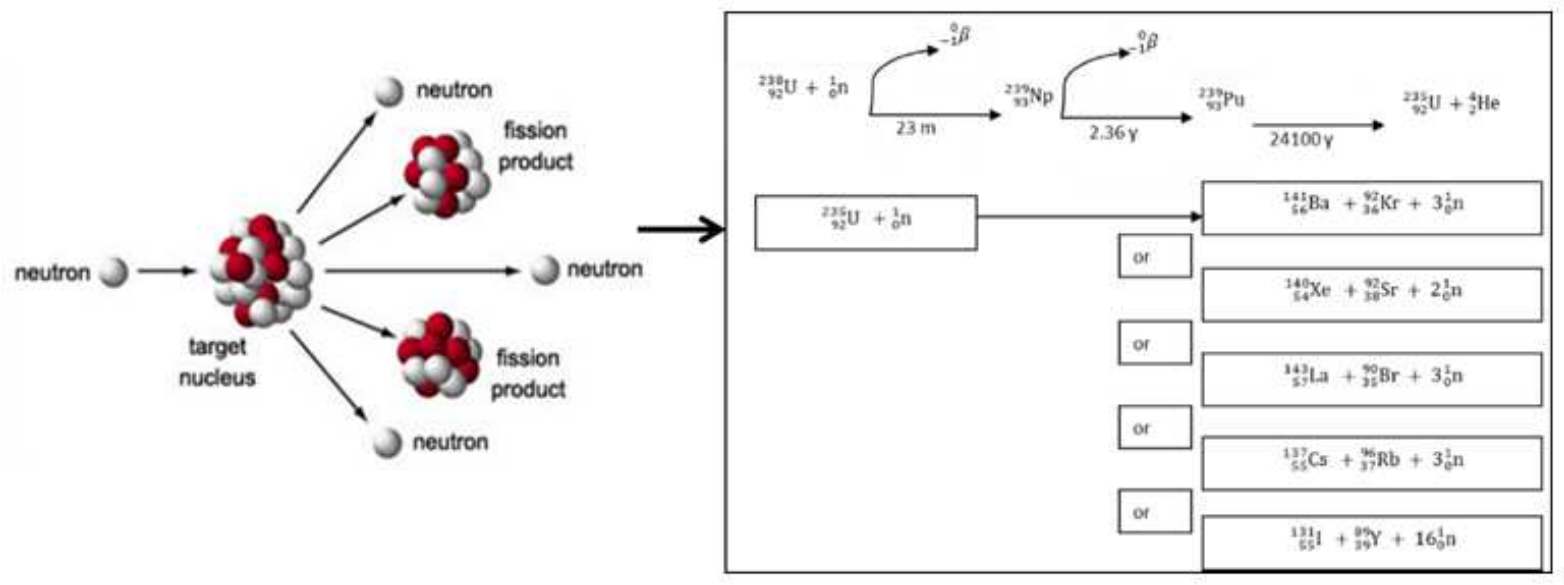

Figure 2: Fission Product for U-235 and U-238

Mathematical modelling has played an important role in the development of PWR. There have been various researchers such as [2], [3] and [4] who have produced mathematical models for PWR systems. However in 2010, Tahir et al. [4] presented the concept of modelling using graph representation of a system based on chemical compound and its reactions as vertices and edges respectively. This technique was then implemented by Ashaari et al. [5] into modelling of a primary system of PWR. In this paper, the authors introduce the concept of fuzzy in 
modelling the PWR. Both crisp and fuzzy models of PWR will be compared and discussed.The next section presents some definitions on fuzzy graph and fuzzy autocatalytic set (FACS).

\section{Fuzzy Graph}

Graph is defined as networks of points that are connected by links [6]. It describes a set of lines which connectsa set of points [7].

Definition $1[6]$ A directed graph $G=G(V, E)$ is defined by a set of "vertices" also known as "nodes" and a set of "edges" or "links", where each edge is an ordered pair of vertices.

A set of vertices or nodes can be represented as

$$
V=\left\{v_{1}, v_{2}, v_{3}, \ldots, v_{n}\right\} \text { and } E=\left\{e_{1}, e_{2}, e_{3}, \ldots, e_{m}\right\}
$$

respectively. An autocatalytic set is defined as a set of catalytically compounds [8]. Jain and Krishna [9] introduced the definition of an autocatalytic set in the form of a graph.

Definition 2[9] An autocatalytic set (ACS) is a sub graph, each of whose nodes have at least one incoming link from a node belonging to the same sub graph (see Figure 3).

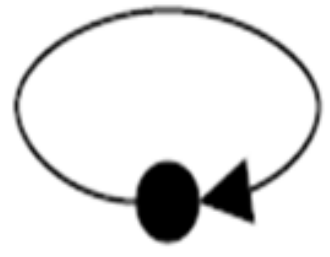

(a)

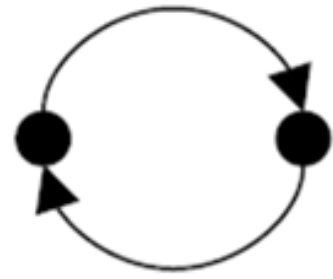

(b)

Figure 3: (a) A 1-cycle, the simplest ACS. (b) A 2- cycle

In 1965, Zadeh [10] introduced a mathematical conceptcalled fuzzy set which then led to a new way of modelling. It has been used in various disciplines and has opened a new history in graph theory. The implementation of fuzzy into graph was first introduced by Rosenfeld [11] as follow:

Definition 3[11] Fuzzy graph $G=(\sigma, \mu)$ is a pair of functions $\sigma=S \rightarrow[0,1]$ and $\mu=$ $S \times S \rightarrow[0,1]$ for $\forall x, y \in S$ with $\mu(x, y) \leq \sigma(x) \wedge \sigma(y)$.

In the same year, Yeh and Bang [12] presented another refined definition of a fuzzy graph.

Definition 4[12] A Fuzzy graph $G=(V, R)$ is defined as a pair such that $V$ is a set of vertices and $R$ is a fuzzy set of edges.

Definition 4 states that the fuzziness occurs on edges and not on vertices. The value of on edge is determined by the value of its membership value which lies from 0 to 1 (see Figure 4 ). 


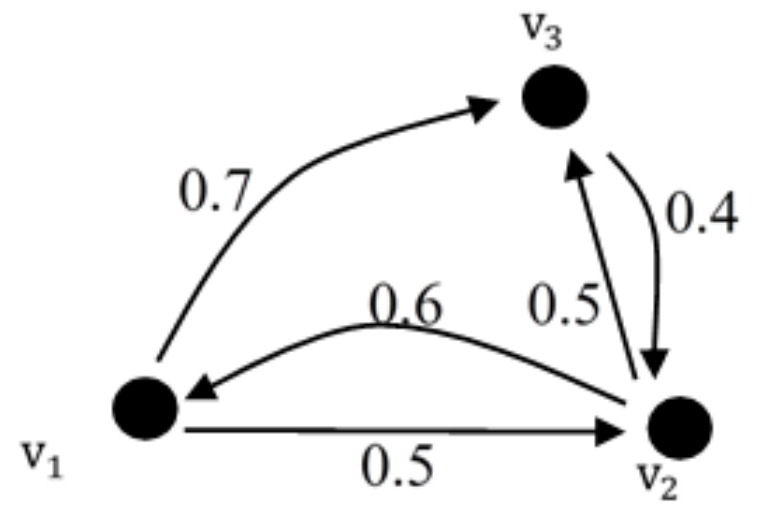

Figure 4: A Fuzzy Graph

In 2002, Blue et al. [13] introduced five types of possible fuzziness for graph. This is famously known as taxonomy of fuzzy graphs. The complete descriptions of taxonomy of fuzzy graphs are given in [13]. Tahir et al. [14] summarized the taxonomy developed by [13] as follow:

The fuzzy graph is a graph $G_{F}$ that satisfies one of the fuzziness ( $G_{F}^{i}$ of the $i^{\text {th }}$ type) or any of its combinations:

Type 1: $G_{F}^{1}=\left\{G_{1_{F}}, G_{2_{F}}, G_{3_{F}}, \ldots, G_{n_{F}}\right\}$ where fuzziness is on $G_{i_{F}}$ for $i=1,2,3, \ldots, \mathrm{n}$.

Type 2: $G_{F}^{2}=\left\{V, E_{F}\right\}$ where edges are fuzzy.

Type 3: $G_{F}^{3}=\left\{V, E\left(t_{F}, h_{F}\right)\right\}$ where both vertices and edges are crisp with edges have fuzzy heads and tails.

Type 4: $G_{F}^{4}=\left\{V_{F}, E\right\}$ where vertices are fuzzy.

Type 5: $G_{F}^{5}=\left\{V, E\left(w_{F}\right)\right\}$ where both vertices and edges are crisp with fuzzy weights.

This properties obtained in fuzzy are also induced to autocatalytic set. It was introduced by Tahir et al. [4] and is known as fuzzy autocatalytic set (FACS).

Definition 5 [4] Fuzzy Autocatalytic Set (FACS) is a sub graph each of whose vertices have at least one incoming link with membership value $\mu\left(e_{i}\right) \in(0,1], \forall e_{i} \in E$.

Further, Jain and Krishna [15] presented a mathematical equation for dynamicity of a graph as follows:

$$
x_{i}^{\prime}=\sum_{j=1}^{n} c_{i j} x_{j}-x_{i} \sum_{j, k=1}^{n} c_{k j} x_{j}
$$

where $c_{i j}$ and $c_{k j}$ are the entries of matrix and the set of variable $x_{i}$ is designated as $\boldsymbol{x}=$ $\left\{x_{1}, x_{2}, x_{3}, \ldots x_{n}\right\}$, which stands for the relative population of the $i^{\text {th }}$ term. Its dynamicity preserves the normalization of $x$ is,

$$
\sum_{i=1}^{n} x_{i}^{\prime}=0
$$

Next section presents the transformation of a crisp graph of PWR into a fuzzy graph of ACS. 


\section{Implementation of FACS on PWR}

The crisp graph model of primary system of PWR in [5] is illustrated in Figure 5.

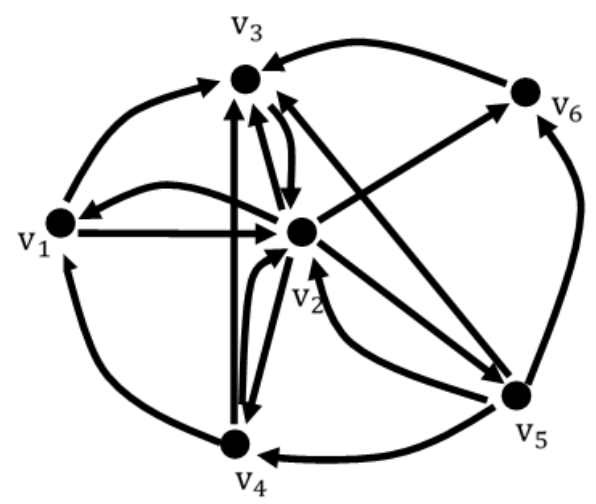

$$
\begin{aligned}
& v_{1}: \text { Fuel } \\
& v_{2}: \text { Moderator } \\
& v_{3}: \text { Corrosion } \\
& v_{4}: \text { Boron } \\
& v_{5}: \text { Nitrogen } \\
& v_{6}: \text { Chlorines }
\end{aligned}
$$

Figure 5: An Autocatalytic Set of Primary System $\left(G_{P S}\right)$

The vertex of fuel presents $\mathrm{UO}_{2}$ and its fission product. Meanwhile, the moderator is the water compound, and corrosion is the particle of metal involve in PWR. Boron includes boric acid. On the other hand, nitrogen represents the group of possible nitrogen compounds such as nitric acid, ammonia and ammonia hydroxide. These information are summarized in Table 1.

Graph $G_{F_{P S}}$ consists of 16 edges with 16 membership values. Each membership value for fuzzy edge connectivity is determined by its weight of compound. Data for the primary system are obtained from PWR type AP1000 [18, 19, and 20]. The fuzzy graph of primary system, $G_{F_{P S}}$ is presented in Figure 6 .

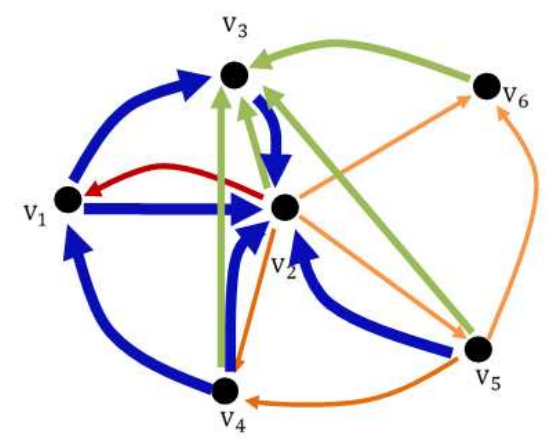

$$
\begin{aligned}
& v_{1}: \text { Fuel } \\
& v_{2}: \text { Moderator } \\
& v_{3}: \text { Corrosion } \\
& v_{4}: \text { Boron } \\
& v_{5}: \text { Nitrogen } \\
& v_{6}: \text { Chlorines }
\end{aligned}
$$

Figure 6: Fuzzy Graph of Primary System PWR $\left(G_{F_{P S}}\right)$

Fuzzy graph $G_{F_{P S}}$ consists of different colour and thickness due to the different range of membership values of fuzzy edge connectivity and also different values of connectivity between vertices. In summary, each colour and the thickness of an edge reflects its connectivity (see Figure 6). In the following section, the FACS of $G_{F_{P S}}$ is discussed. 
Table 1: The Edges of Graph $G_{P S}$

\begin{tabular}{|c|c|c|}
\hline Vertices & Edge & Descriptions \\
\hline$\left(\mathrm{v}_{1}, \mathrm{v}_{3}\right)$ & $\mathrm{e}_{1}$ & $\begin{array}{l}\text { Fuel is catalyzed to form corrosion. The balance equation is } \\
\qquad I_{2}+Z n \rightarrow Z n I_{2}\end{array}$ \\
\hline$\left(\mathrm{v}_{2}, \mathrm{v}_{1}\right)$ & $\mathrm{e}_{2}$ & Fuel compound such as $R b O_{2}$ forms when $R b$ reacts with oxygen \\
\hline$\left(\mathrm{v}_{1}, \mathrm{v}_{2}\right)$ & $\mathrm{e}_{3}$ & $\begin{array}{l}\text { The balance equation below presents the formation of moderator by hydrogen iodide. } \\
\qquad \mathrm{O}_{2}+4 \mathrm{HI} \rightarrow 2 \mathrm{H}_{2} \mathrm{O}+2 \mathrm{I}_{2} \\
\text { Thus, fuel is catalyzed in the formation of the moderator }\end{array}$ \\
\hline$\left(\mathrm{v}_{4}, \mathrm{v}_{1}\right)$ & $\mathrm{e}_{4}$ & $\begin{array}{l}\text { The role of boron is to control the reaction of fuel. Boron tribromide is one of fuel } \\
\text { compounds that is formed when } B r_{2} \text { reacts to Boron. } \\
\qquad 3 B r_{2}+2 B \rightarrow 2 B B r_{3}\end{array}$ \\
\hline$\left(\mathrm{v}_{4}, \mathrm{v}_{3}\right)$ & $\mathrm{e}_{5}$ & $\begin{array}{l}\text { Boron catalyzes the formation of corrosion. An example, boric acid corrodes almost } \\
\text { entire bolts in cooling system isolation valve of San Onofre Unit } 2[16]\end{array}$ \\
\hline$\left(\mathrm{v}_{2}, \mathrm{v}_{4}\right)$ & $\mathrm{e}_{6}$ & $\begin{array}{l}\text { The formation of boric acid occurs when Diborane }\left(\mathrm{B}_{2} \mathrm{H}_{6}\right) \text { reacts with moderator. } \\
\qquad \mathrm{B}_{2} \mathrm{H}_{6}+6 \mathrm{H}_{2} \mathrm{O} \rightarrow 2 \mathrm{~B}(\mathrm{OH})_{3}+6 \mathrm{H}_{2}\end{array}$ \\
\hline$\left(\mathrm{v}_{2}, \mathrm{v}_{3}\right)$ & $\mathrm{e}_{7}$ & Excess oxygen is one of the factor effects corrosion rate $[17]$ \\
\hline$\left(\mathrm{v}_{5}, \mathrm{v}_{3}\right)$ & $\mathrm{e}_{8}$ & $\begin{array}{l}\text { Nitrogen is known to be either acid or base compound. Nitric is an acidic compounds } \\
\text { which increases corrosion rate [17] }\end{array}$ \\
\hline$\left(\mathrm{v}_{3}, \mathrm{v}_{2}\right)$ & $\mathrm{e}_{9}$ & $\begin{array}{l}\text { Corrosion catalyzes the formation of moderator. An example of it is ferrous oxide. } \\
\text { When hydrogen reacts with } \mathrm{Fe}_{2} \mathrm{O}_{3} \text {, the moderator is formed[17]. } \\
\qquad 3 \mathrm{Fe}_{2} \mathrm{O}_{3}+\mathrm{H}_{2} \rightarrow 2 \mathrm{Fe}_{3} \mathrm{O}_{4}+\mathrm{H}_{2} \mathrm{O}\end{array}$ \\
\hline$\left(\mathrm{v}_{2}, \mathrm{v}_{6}\right)$ & $\mathrm{e}_{10}$ & $\begin{array}{l}\text { Chlorine is formed when the hydrochloric acid ( } \mathrm{HCl}) \text { reacts with moderator. } \\
\qquad \mathrm{HCl}+\mathrm{H}_{2} \mathrm{O} \rightarrow \mathrm{H}_{3} \mathrm{O}^{+}+\mathrm{Cl}^{-}\end{array}$ \\
\hline$\left(\mathrm{v}_{2}, \mathrm{v}_{5}\right)$ & $\mathrm{e}_{11}$ & $\begin{array}{l}\text { The relationship between moderator and nitrogen is described as follow, } \\
\qquad 2 \mathrm{~N}_{2}+5 \mathrm{O}_{2}+2 \mathrm{H}_{2} \Leftrightarrow 4 \mathrm{HNO}_{3}\end{array}$ \\
\hline$\left(\mathrm{v}_{5}, \mathrm{v}_{2}\right)$ & $\mathrm{e}_{12}$ & $\begin{array}{l}\text { The increasing of temperature inside PWR caused nitric acid to decompose. This } \\
\text { reaction produces the formation of the moderator. } \\
\qquad 4 \mathrm{HNO}_{3} \rightarrow 2 \mathrm{H}_{2} \mathrm{O}+4 \mathrm{NO}_{2}+\mathrm{O}_{2}\end{array}$ \\
\hline$\left(\mathrm{v}_{5}, \mathrm{v}_{4}\right)$ & $\mathrm{e}_{13}$ & $\begin{array}{l}\text { Boric acid is neutralized by ammonia. The chemical reaction between them forms } \\
\text { boron nitride. } \\
\qquad B(\mathrm{OH})_{3}+\mathrm{NH}_{3} \rightarrow \mathrm{BN}+3 \mathrm{H}_{2} \mathrm{O}\end{array}$ \\
\hline$\left(\mathrm{v}_{6}, \mathrm{v}_{3}\right)$ & $\mathrm{e}_{14}$ & Hydrochloric $(\mathrm{HCl})$ is an acidic compound which increase corrosion rate [17] \\
\hline$\left(\mathrm{v}_{5}, \mathrm{v}_{6}\right)$ & $\mathrm{e}_{15}$ & $\begin{array}{l}\text { The chemical reaction between } \mathrm{NH}_{3} \text { with } \mathrm{HCl} \text { forms ammonium chlorides. } \\
\qquad \mathrm{NH}_{3}+\mathrm{HCl} \rightarrow \mathrm{NH}_{4} \mathrm{Cl}\end{array}$ \\
\hline$\left(\mathrm{v}_{4}, \mathrm{v}_{2}\right)$ & $\mathrm{e}_{16}$ & $\begin{array}{l}\text { At higher temperature, } \mathrm{H}_{3} \mathrm{BO}_{3} \text { is decomposed into } \mathrm{HBO}_{2} \text { and moderator. The bal- } \\
\text { ance equation is presented as follow: } \\
\qquad \mathrm{H}_{3} \mathrm{BO}_{3} \rightarrow \mathrm{HBO}_{2}+\mathrm{H}_{2} \mathrm{O}\end{array}$ \\
\hline
\end{tabular}




\section{Result and Discussion}

Graph $G_{F_{P S}}$ is an ACS by the Definition 1.2. The adjacency matrix of graph $G_{F_{P S}}$ is constructed based on membership values of its connectivity.

$$
C_{F_{P S}}=\left(\begin{array}{cccccc}
0 & 0.3272 & 0 & 0.9241 & 0 & 0 \\
0.9999 & 0 & 0.9999 & 0.9999 & 0.9999 & 0 \\
0.9127 & 0.5960 & 0 & 0.5960 & 0.5960 & 0.5960 \\
0 & 0.0400 & 0 & 0 & 0.0400 & 0 \\
0 & 0.0644 & 0 & 0 & 0 & 0 \\
0 & 0.0507 & 0 & 0 & 0.0507 & 0
\end{array}\right)
$$

By substituting in gmatrix $C_{F_{P S}}$, (3) and the ratio value of weight for each variable in PWR into (1), the dynamic concentration of $G_{F_{P S}}$ is obtained.

$$
\left(\begin{array}{l}
x_{1}^{\prime} \\
x_{2}^{\prime} \\
x_{3}^{\prime} \\
x_{4}^{\prime} \\
x_{5}^{\prime} \\
x_{6}^{\prime}
\end{array}\right)=\left(\begin{array}{r}
-0.1266 \\
-0.0458 \\
0.1659 \\
0.0180 \\
-0.0073 \\
-0.0043
\end{array}\right)
$$

The negative signs in (4) indicate that the respective compounds are consumed during the operation. Next, the dynamic graph for $G_{F_{P S}}$ is evaluated using system dynamic variable selection (SDVS(C) software. The SDVS(C) has received copyright (C)2015 Universiti Teknologi Malaysia-All Right Reserved [21]. Two vertices are determined for each fuzzy graph at the end of simulations (see Table 2). The variables are the outputs of PWR primary system.

Table 2 shows series of dynamic fuzzy graph for primary systems of PWR. The set of compounds that remains at a given time, $t$ for primary system are as follows.

$$
\begin{aligned}
t_{0} & \rightarrow \text { (Fuel,Moderator,Corrosion,Boron,Nitrogen, Chlorine) } \\
t_{1} & \rightarrow \text { (Fuel,Moderator,Corrosion,Nitrogen, Chlorine) } \\
t_{2} & \rightarrow \text { (Fuel,Moderator,Corrosion, Nitrogen ) } \\
t_{3} & \rightarrow \text { (Fuel,Moderator, Corrosion) } \\
t_{4} & \rightarrow \text { (Moderator, Corrosion) }
\end{aligned}
$$

Table 3 shows the dynamic concentrations for crisp and fuzzy graphs of the primary system. Crisp graph is a graph with the value of its edges can be only either 0 or 1.

Table 3 shows that the value for fuel is negative which indicates the amount of fuel has been consumed as time increased. This behavior was right since $U_{2}$ is the main compound needed to heat the moderator. It has been justified by PWR waste reports in [20]. Graph $G_{F_{P S}}$ shows that the nitrogen and chlorine are negative for their rates of change. This characteristic indicates that both compounds are consumed during the operation. The negative sign for nitrogen was justified by [17]. The amount of nitrogen decreased due to major role in controlling the $p H$ rate. The activation of oxygen inside the moderator caused the formation of nitrogen-16. Nitrogen-16 is a strong gamma radiation emitter with a half-life of around 7.11 second [19]. This showed 
Table 2: Dynamic Graph of FACS $G_{F_{P S}}$

\begin{tabular}{|l|c|c|}
\hline Variable of Graph $\boldsymbol{G}_{\boldsymbol{F}_{\boldsymbol{P}}}$ & PFE & Description \\
\hline$\left(\begin{array}{l}\text { Fuel } \\
\text { Moderator } \\
\text { Corrosion } \\
\text { Boron } \\
\text { Nitrogen } \\
\text { Chlorine }\end{array}\right)$ & $\left(\begin{array}{l}0.2293 \\
0.7589 \\
0.6066 \\
0.0269 \\
0.0410 \\
0.0341\end{array}\right)$ & Boron is depleted \\
\hline $\left.\begin{array}{l}\text { Fuel } \\
\text { Moderator } \\
\text { Corrosion } \\
\text { Nitrogen } \\
\text { Chlorine }\end{array}\right)$ & $\left(\begin{array}{l}0.2173 \\
0.7601 \\
0.6099 \\
0.0428 \\
\mathbf{0 . 0 3 5 6}\end{array}\right)$ & \\
\hline$\left(\begin{array}{l}\text { Fuel } \\
\text { Moderator } \\
\text { Corrosion } \\
\text { Nitrogen }\end{array}\right)$ & $\left(\begin{array}{l}0.2209 \\
0.7652 \\
0.6031 \\
0.0435\end{array}\right)$ & Chlorine is depleted \\
\hline$\left(\begin{array}{l}\text { Fuel } \\
\text { Moderator } \\
\text { Corrosion }\end{array}\right)$ & $\left(\begin{array}{l}0.2281 \\
0.7623 \\
0.6057\end{array}\right)$ & Nitrogen is depleted \\
\hline
\end{tabular}

Table 3: Dynamics Concentration for Graph $G_{P S}$ and $G_{F_{P S}}$

\begin{tabular}{|c|c|c|c|}
\hline Vertices & Variable & $\begin{array}{c}\text { Rate of change for } \\
\text { crisp graph } \boldsymbol{G}_{\boldsymbol{P S}}\end{array}$ & $\begin{array}{c}\text { Rate of change for } \\
\text { fuzzy graph } \boldsymbol{G}_{\boldsymbol{F}_{\boldsymbol{S}}}\end{array}$ \\
\hline $\mathrm{v}_{1}$ & Fuel & -0.2363 & -0.1266 \\
\hline $\mathrm{v}_{2}$ & Moderator & -0.9002 & -0.0458 \\
\hline $\mathrm{v}_{3}$ & Corrosion & -0.1189 & 0.1659 \\
\hline $\mathrm{v}_{4}$ & Boron & 0.4806 & 0.0180 \\
\hline $\mathrm{v}_{5}$ & Nitrogen & 0.3630 & -0.0073 \\
\hline $\mathrm{v}_{6}$ & Chlorine & 0.4117 & -0.0043 \\
\hline
\end{tabular}


that nitrogen is easily diminished. Chlorine decreases due to the neutralization process by nitrogen, i.e. feed and bleed. The corrosion is positive for fuzzy graph while for the crisp graph is negative. The corrosion should be positive since PWR of a nuclear power plant operates more than one year as stated in $[17,18]$. This caused the corrosion to increase. The series of dynamic graph between crisp and fuzzy graphs for the primary system are presented in Table 4.

Table 4: Sequence of Depletion for Graph $G_{P S}$ and $G_{F_{P S}}$

\begin{tabular}{|c|l|l|}
\hline & Crisp graph $\boldsymbol{G}_{P S}$ & Fuzzy graph $\boldsymbol{G}_{F_{P S}}$ \\
\hline \multirow{4}{*}{ Sequence of variables depleted } & 1. Nitrogen & 1. Boron \\
& 2. Boron & 2. Chlorine \\
& 3. Chorine & 3. Nitrogen \\
& 4. Fuel & 4. Fuel \\
\hline The remaining variables & Moderator and Corrosion & Moderator and Corrosion \\
\hline
\end{tabular}

Table 4 shows that boron is the first to be depleted for the fuzzy graph. The amount of boron is added approximately 100 gallons per minute (22.71 m3/hour) into the system [19]. This shows boron is easily diminished. On the other hand, moderator and corrosion survive in the primary system for crisp and fuzzy graph. The moderator appears at the end of the process due to the moderator's role, which prevents PWR from overheating. On the other hand, corrosion exists due to chemical reactions and the long term operation of PWR. Hence, $G_{F_{P S}}$ is likely to present the actual process of PWR primary system than $G_{P S}$.

\section{Conclusion}

The FACS is successfully implemented in modelling of PWR primary system. The fuzzy edge connectivity for $G_{F_{P S}}$ is evaluated using SDVS. The obtained result of $G_{F_{P S}}$ concurred with real data of a primary system reported in [19].

\section{Acknowledgment}

This work has been supported by Ibnu Sina Institute for Scientific and Industrial Research, UTM, MyBrain15 from Ministry of High Education Malaysia, Ministry of High Education (MOHE), STEM Grant with vote no. A. J091002.5600.07397, University Teknologi Malaysia, FRGS (4F756) and GUP (13H17).

\section{References}

[1] Sovacool, B. K. A critical evaluation of nuclear power and renewable electricity in Asia. Journal of Contemporary Asia. 2010. 40(3): 369-400

[2] Gábor, A., Fazekas, C., Szederkényi, G., \& Hangos, K. M. Modeling and identification of a nuclear reactor with temperature effects and xenon poisoning. In Industrial Electronics, 2009. IECON'09. 35th Annual Conference of IEEE. 3-5 November. IEEE, 2009. 1639-1644

[3] Wilson K. L. Advance Pressurized Water Reactor Simulation. Canada: Cassiopeia Technologies Inc. 2009 
[4] Tahir, A., Sabariah, B, and Khairil, A. A. Modeling a clinical incineration process using fuzzy autocatalytic set. Journal of Mathematical Chemistry. 2010. 47(4): 1263-1273

[5] Ashaari, A., Ahmad, T., Shamsuddin, M., \& Mohammad, W. M. W. An Autocatalytic model of a pressurized water reactor in a nuclear power generation. In International Conference on Soft Computing in Data Science. Singapore: Springer. September 2015. 106-115.

[6] Balakrishnan, R., and Ranganathan, K. A Textbook of Graph Theory. New York: Springer Science and Business Media. 2012

[7] Epp, S. S. Discrete Mathematics with Applications. Boston: PWS Publishing Company. 1993

[8] igen, M., McCaskill, J. and Schuster, P. The molecular quasi-species. Advanced Chemistry Physics. 1989. 75: 149-263

[9] Jain, S. and Krishna, S. Autocatalytic sets and the growth of complexity in an evolutionary model. Physical Review Letters. 1998. 81: 5684-5687

[10] Zadeh, L.A. Fuzzy sets. Information and Control. 1965. 8: 338-353

[11] Rosenfeld, A. Fuzzy graphs. In Zadeh, L. A., Fu, K.S., and Shimura, M. (Eds.) Fuzzy Sets and their Applications. New York: Academic Press. 1975

[12] Yeh, R. T., \& Bang, S. Y. Fuzzy relations, fuzzy graphs, and their applications to clustering analysis. Fuzzy Sets and Their Applications, 1975. 125-149

[13] Blue, M., Bush, B., and Puckett, J. Unified approach to fuzzy graph problem. Fuzzy Set System. 2002. 125: 355-368

[14] Tahir, A., Sabariah, B, and Khairil, A. A. Graphical Presentation of a Clinical Waste Incinerations Proses. Paper presented at the 10th National Symposium of Mathematical Sciences, Johor Bahru, 2002

[15] Jain, S. and Krishna, S. Graph Theory and the Evolution of Autocatalytic Networks. In Bornholdt, S. and Schuster, H. G. (Eds.) Handbook of Graphs and Networks. Berlin: John Wiley and VCH Publishers. 2003. 355-395

[16] O'Neill, A. S., and Hall, J. F. Boric acid corrosion of carbon and low-alloy steel pressureboundary components in PWRs: Final report (No. EPRI-NP-5985). Electric Power Research Inst., Palo Alto, CA (USA): Combustion Engineering, Inc., Windsor, CT (USA), 1988

[17] Gedeon, P. G. Fundamentals of Chemistry, Nuclear Engineering and Technology. New York: Continuing Education and Development, Inc. 1993

[18] UKP-GW-GL-057. UK AP1000 NDA Data Sheet Submission. Pittsburgh: Westinghouse Electric Company LLC2010

[19] EPS-GW-GL-700. AP1000 European Design Control Document. Pittsburgh: Westinghouse Electric Company LLC. 2009.

[20] UKP-GW-GL-790, Revision 4. UK AP1000 Environment Report. Pittsburgh: Westinghouse Electric Company LLC 2011.

[21] Ashaari, A., Ahmad, T., Zenian, S., \& Shukor, N. A. Selection probe of EEG using dynamic. graph of autocatalytic set (ACS). In International Conference on Soft Computing in Data Science. Springer Singapore. 2016. 25-36 